\title{
High Temperature Corrosion in Nickel-Chromium Alloys
}

\author{
by Norman Spooner, John M. Thomas, and L. Thomassen
}

$\mathbf{N}$ I-CR and some Ni-Cr-Fe alloys, when used as electrical resistance heating elements in reducing atmospheres, at times suffer rapid breakdowns due to so-called "green rot." These reducing atmospheres are most frequently used in bright annealing and heat-treating furnaces which are kept for long periods of time at $1500^{\circ}$ to $1800^{\circ} \mathrm{F}$. The green rot is a preferential oxidation of the chromium in the alloy to such an extent that the remaining metal frequently becomes ferromagnetic. The Curie point (magnetic transition point) at room temperature for a pure $\mathrm{Ni}-\mathrm{Cr}$ alloy is known to be at about 7 pct $\mathrm{Cr}^{1}{ }^{1}$ This represents a severe loss in chromium for one popular grade of resistance alloy, which is nominally 80 pct $\mathrm{Ni}-20$ pct $\mathrm{Cr}$. The formation of oxides along the grain boundaries makes the ribbon brittle and gives the fracture a green, earthy appearance-hence the name.

The authors have studied this phenomenon, simulating the industrial conditions by heating resistance ribbons in various reducing atmospheres, such as moist hydrogen or the atmosphere specified in the ASTM test. ${ }^{2}$ This atmosphere contains 16 pct $\mathrm{H}_{2}$, 10 pct $\mathrm{CO}, 4$ pet $\mathrm{CO}_{2}, 1$ pet $\mathrm{CH}_{4}, 1.5$ to 2.5 pet $\mathrm{H}_{2} \mathrm{O}$, balance $\mathrm{N}_{2}$.

Little success was had in producing severe corrosion with the commercial 80 pet $\mathrm{Ni-20}$ pct $\mathrm{Cr}$ alloys. It had been noticed, however, that 90 pct $\mathrm{Ni}-$ 10 pct $\mathrm{Cr}$ alloy wires deteriorated very rapidly when placed in the bottom of narrow thermocouple protection tubes. The bottoms of the tubes with the wires were heated in air. This took place both in porcelain tubes and in Inconel* tubes either with Inconel is a heat and corrosion resistant alloy manufactured by
the International Nickel Co. and has a nominal composition of 78
pct $\mathrm{Ni}, 14$ pct $\mathrm{Cr}$, balance $\mathrm{Fe}$.

the cold end open or loosely stoppered with asbestos. On examination the wires showed microstructures which would be classified as green-rot corrosion.

Subsequent investigations with various alloy wires confirmed the observation that corrosion occurred in some wires, including 80 pct Ni-20 pet $\mathrm{Cr}$ alloys, much more rapidly in such tubes than had occurred previously in test atmospheres mentioned above.

When 90 pct $\mathrm{Ni}-10$ pct $\mathrm{Cr}$ alloys are oxidized with an abundant air supply, the oxide coat consists of both nickel and chromium oxides. In this case thermodynamic equilibrium between the oxides is not established.

N. SPOONER is Metallurgical Engineer, Hoskins Manufacturing Co., Detroit, J. M. THOMAS, Junior Member AIME, formerly with Hoskins Manufacturing Co., is now with Scientific Laboratory, Ford Motor Co., Dearborn, and L. THOMASSEN is Professor of Chemical and Metallurgical Engineering, University of Michigan, Ann Arbor, Mich.

TN 164E. Manuscript, June 27, 1952; revision, April 20, 1953.
However, when oxidized 90 pct $\mathrm{Ni}-10$ pct $\mathrm{Cr}$ alloy specimens were heated to $1500^{\circ}$ to $1800^{\circ} \mathrm{F}$ inside small diameter tubes, the oxide coat transformed to a bright metallic outer layer of nickel or nickel-rich alloy, beneath which appeared a green oxide, followed by intergranularly attacked metal. The obvious explanation is that in the narrow tubes, thermodynamic equilibrium is being established according to the equation

$$
\mathrm{NiO}+\mathrm{Cr} \text { (in alloy) } \rightarrow \mathrm{Ni}+\mathrm{Cr}_{2} \mathrm{O}_{3}
$$

This reaction is favored due to the fact that the oxygen pressure over nickel oxide is more than $10^{10}$ times the oxygen pressure over the green chromium oxide. The initial oxygen in the tubes is depleted very rapidly by oxidation of the wire and of the tube, if it is metallic. A confirmation of the occurrence of the reaction, reduction of $\mathrm{NiO}$ by the chromium in the alloy, was obtained by putting oxidized nickel foil into an evacuated quartz tube along with a piece of bright 90 pct $\mathrm{Ni}-10$ pct $\mathrm{Cr}$ alloy ribbon, and heating the tube at $1820^{\circ} \mathrm{F}$ for a number of hours. The nickel oxide on the foil was completely reduced to pure nickel, leaving a bright foil. The 90 pct $\mathrm{Ni}-10$ pct $\mathrm{Cr}$ alloy became strongly magnetic and showed the typical green-rot structure. Weights of the samples before and after testing showed the weight loss of the foil to approximately equal the weight gain of the ribbon. Evidently the bottom of long, narrow protection tubes, stoppered or not, may under certain conditions act just as the sealed quartz tubes in respect to being a confined space in which oxygen is not freely replenished. This condition of oxygen depletion can be prevented by introducing a small amount of air into the bottom of the tube.

Many conditions becloud the green-rot phenomenon, such as carburization, sulphidization, and the presence of other corrosive agents. However, these experiments have shown that the basic reaction is a case of internal oxidation which can occur simply by adjusting the oxygen pressure to a low enough level so that the atmosphere will leave the nickel intact and oxidize the chromium. The action of the other agents in commercial atmospheres can then be taken up as individual cases.

From these and numerous other tests completed to date or still in progress, it is believed that a more critical evaluation of electrical resistance alloys for their resistance to green-rot corrosion can be made. A much better understanding of the mechanism for this type of corrosion should also result. A more complete report on these experiments will be published later.

\section{References}

${ }^{1}$ V. Marion: Ann. Physik (1937) y, p. 502.

${ }^{2}$ ASTM Test for Effect of Controlled Atmospheres upon Alloys in Electric Furnaces. B181-43.

\section{Correction}

In the May 1953 issue: TP 3521E Discussion: Solubility of Carbon and Oxygen in Molybdenum by W. E. Few and G. K. Manning, discussion by N. A. Gokcen: p. 747, first column, the fifth, sixth, and seventh lines should be the first, second, and third lines, followed by the present first, second, third, fourth, eighth, ninth, and tenth lines. 